\title{
Epidural anesthesia: Views and outcomes of women in labor in a Nigerian hospital
}

\author{
Page $\mid 250$ S. Fyneface-Ogan, C. N. Mato, S. E. Anya ${ }^{1}$ \\ Department of Anaesthesiology, College of Health Sciences, University of Port Harcourt, Choba-Port Harcourt, \\ Nigeria; ${ }^{1}$ School of Medicine and Allied Health Sciences, University of the Gambia, Kanifing, The Gambia
}

Correspondence to: Dr. S. Fyneface-Ogan, Department of Anaesthesiology, Faculty of Clinical Sciences, College of Health Sciences, University of Port Harcourt, Choba-Port Harcourt, Nigeria. E-mail: soglonye@yahoo.com

\begin{abstract}
Background: Pain during childbirth is a well known cause of dissatisfaction amongst women in labor. The use of epidural analgesia in labor is becoming widespread due to its benefit in terms of pain relief.

Method: After approval of the local Ethics Committee on Research and obtaining informed written consent, 50 American Society of Anesthesiologists (ASA) class I-II consecutive multiparous women in labor requesting pain relief were enrolled in this prospective study. After providing description of the two options of pain relief available to them, they were allocated into two groups according to their request-to receive either parenteral opioid/sedative or epidural labor analgesia. Both groups received analgesia of choice at 4-cm cervical os dilatation. The epidural group received $0.125 \%$ plain bupivacaine, while the other group received pentazocine/promethazine intravenously. The time taken to locate the epidural space, catheter-related complications encountered and the amount of intravenous fluid used were documented.

Result: The two groups were comparable in terms of socio-demographic data. The mean duration of the first and second stages of labor, respectively, were significantly shorter in the epidural group when compared with those in the non-epidural group $([P<0.01]$ and $[P<0.02])$. There was no difference in the rate of cesarean delivery between them - epidural analgesia (32\% [8/25]) versus parenteral opioid/sedative (44\% [11/25]), (OR, 0.60; 95\% CI, 0.19-1.90). The maternal blood loss from delivery was minimal, with no statistical difference between the two groups $(P=0.27)$. The neonatal outcome was the same in both groups. Closed questionnaire showed that the overall experience of labor was much better (it was also better than expected) in the epidural group when compared with that in the non-epidural group ( $80 \%$ versus $4 \%$ ). Eighteen $(72 \%)$ women had inadequate pain relief in the non-epidural group as compared to $2(8 \%)$ women in the epidural group. Conclusion: The study shows that epidural labor analgesia is acceptable to women in our setting. More women in the epidural analgesia group were satisfied with the experience of labor than those who did not receive this form of analgesia than among those who received parenteral opioid/sedative.
\end{abstract}

Keywords: Analgesia, epidural, labor, views, women

\section{Résumé}

Arrière-plan: Douleur pendant l'accouchement est un bien connu d'origine du mécontentement chez les femmes de berce. L'utilisation de analgésie epidural du travail devient généralisée en raison de son avantage en termes de l'allégement de la douleur.

Méthode: Après l'approbation d'éthique local Comité de recherche et de l'obtention de consentement, 50 ASA classe I-II écrit informé femmes multiparous consécutives du travail qui demande le soulagement des douleurs étaient inscrits à Cette étude prospective. Description suivante des deux options de l'allégement de la douleur à leur disposition, ils ont été allouées en deux groupes selon leur demande soit à recevoir parvoie parentérale Opioïde/sédatif ou epidural analgésie du travail. Les deux groupes reçu analgésie de choix à la dilatation du col utérin os 4 centimètre. Le groupe epidural a reçu bupivacaine plaine de $0.125 \%$ tandis que l'autre reçu pentazocine/promethazine par voie intraveineuse. Le temps nécessaire pour localiser l'epidural espace, cathéter des complications rencontrées et le montant d'intravenous fluides utilisés ont été documentées.

Résultat: Les deux groupes étaient comparables en termes de données socio-démographiques. La durée moyenne 
de la première et seconde étapes du travail était sensiblement plus court $(P<0.01)$ et $(P<0.02)$ dans le groupe epidural que dans le groupe non-epidural. Il n'y avait pas de différence dans la taux de livraison caesarean entre eux; analgésie epidural (32\% [8/25]) versus par voie parentérale Opioïde/sédatif (44\% [11/25]), (ou, 0.60; 95\% CI, $0.19-1.90)$. Le perte de sang maternel de livraison a été minime sans aucune différence statistique entre les deux groupes, $(P=0.27)$. Le résultat néonatal était la même dans les deux groupes. Fermé questionnaires a révélé que l'expérience globale du travail était mieux que prévu avec le groupe epidural que dans le groupe non-epidural $(80 \%$ par rapport à $4 \%$ ). Dix-huit femmes $(72 \%)$ avaient soulagement douleur inadéquates dans le non-epidural groupe par rapport à 2 femmes ( $8 \%$ ) dans le groupe epidural.

Conclusion: L'étude montre que epidural analgésie du travail est acceptable pour les femmes dans notre environnement. Plus de femmes qui reçu epidural analgésie du travail ont été plus satisfaits de l'expérience de travail.

Mots clés: Analgésie, epidural, les femmes, vues du travail

DOI: $10.4103 / 1596-3519.59580$

\section{Introduction}

Pain relief for labor is an important concern for women, both during pregnancy and in childbirth. The use of epidural analgesia in labor is widespread, and the benefits in terms of pain relief are well recognized. In Britain, approximately 100,000 women use this form of pain relief each year. ${ }^{[1]}$ In Nigeria, data on the overall patterns of obstetric pain management are lacking and are limited to surveys concerning service provision rather than genuine patient demand. ${ }^{[2,3]}$ Anecdotal experience also shows that the rate of request for epidural analgesia in labor is low in Nigeria. This has been explained by lack of resources (including manpower) rather than lack of expertise, ${ }^{[4]}$ although lack of patient education and awareness could also be significant contributory factors.

There have been some controversies trailing the use of labor analgesia with regard to the outcome of labor. ${ }^{[5,6]}$ While some studies advance that epidural labor analgesia increases cesarean section rates, ${ }^{[7,8]}$ others say it does not influence these rates. ${ }^{[6,9]}$

Parenteral opioids and sedatives are the most frequently prescribed alternative to women in labor in our hospital. However, in routinely used doses, parenteral opioids and sedatives have been shown to have little or no effect on labor pain. ${ }^{[10]}$ Severe, unrelieved labor pain causes patient dissatisfaction and is known to be associated with postpartum depression and posttraumatic stress disorder. ${ }^{[11]}$

The primary aim of this study was to ascertain the outcome of labor and the views of multiparous Nigerian women in labor under epidural analgesia or parenteral opioids/sedatives in our hospital. The outcome of the study will demonstrate the level of acceptability of the forms of analgesia offered.

\section{Materials and Methods}

Following approval of the local Ethics Committee on Research for this study and also after obtaining informed written consent, 50 ASA class I-II consecutive multiparous women in labor requesting pain relief were enrolled in this prospective study. After providing description of the options of pain relief available to them, they were allocated into two groups according to their request - to receive either parenteral opioid/sedative or epidural labor analgesia. Exclusion criteria included ASA status $>$ II, parturients receiving analgesia prior to enrollment, nulliparity, probable cephalo pelvic disproportion on pelvic examination, and cervical dilatation to $>4 \mathrm{~cm}$. Enrolled patients were randomly assigned to receive either epidural or single-dose combination of pentazocine and phenergan analgesia during labor. An anesthetist managed all parturient women.

Midwives conducted the obstetric management of all parturient women during labor, under the direct supervision of an obstetrician according to the study protocol. Routine intrapartum management of all women included intravenous dextrose saline fluid management and cardiotocograph for monitoring uterine contraction and fetal heart rate. Pelvic examination was performed every 4 hours to evaluate the progress of labor. When the rate of cervical dilatation was less than $1 \mathrm{~cm} /$ hour over a 2-hour period, poor progress of labor was diagnosed. Oxytocin augmentation of labor was commenced if cephalopelvic disproportion had been excluded.

On reaching the decision to administer epidural pain relief, automatic noninvasive arterial blood pressure monitoring and pulse oximetry were commenced, and $10 \mathrm{~mL} / \mathrm{kg}$ of normal saline solution was infused through the dorsum of the non-dominant hand before the procedure. Baseline demographic data and vital signs were recorded before established labor. Basic resuscitation equipments were prepared and kept ready.

With the patient in the sitting position, lumbar 
epidural punctures were performed at the $\mathrm{L}_{3-4}$ interspace using a midline approach with an 18-gauge Tuohy needle. Once the needle was appropriately placed in the epidural space, a 20-gauge multi-orifice epidural catheter (Minipack; Portex Ltd., Kent, UK) was threaded $3 \mathrm{~cm}$ into the space through the cranially directed tip of the needle. Having confirmed a negative aspiration test for blood or cerebrospinal fluid, $3 \mathrm{~mL}$ of $2 \%$ lidocaine with epinephrine $5 \mu \mathrm{g} / \mathrm{mL}$ was injected through the needle as a test dose. The patients were also observed for any increase in heart rate that would indicate intravascular injection of epinephrine and were questioned about dizziness, tinnitus, metallic taste in the mouth or sudden warmth or numbness in the legs. If these responses were negative after 5 minutes, $10 \mathrm{~mL}$ of $0.125 \%$ bupivacaine was injected hourly as a bolus single dose via the epidural catheter. The catheter was fixed to the skin, and the patients were returned to the left lateral position.

The attending anesthetist (that is, not a blinded independent observer) noted any paresthesia during insertion of the catheter, inability to advance the catheter and intravenous or subarachnoid canulation. Intravenous or subarachnoid canulation was detected by aspiration of frank blood or cerebrospinal fluid through the catheter. If intravascular or subarachnoid insertion occurred, the catheter was withdrawn by $1 \mathrm{~cm}$. If this did not lead to withdrawal from the vein or subarachnoid space, the catheter was removed. If it was not possible to thread the catheter, it and the needle were withdrawn together. The procedure was then repeated at the level of $\mathrm{L}_{2-3}$; if unsuccessful again, the patient was excluded from the study and parenteral analgesics were administered.

The blinded anesthetist assessed the following variables: The onset of sensory block (assessed by pinprick); the existence of unblocked segments; the extent of sensory and motor block (assessed by the modified Bromage score); the ability of the parturient woman to cooperate (push on demand) during delivery (graded as "yes" or "no"); and side affects or complications caused by the epidural analgesia, including hypotension (systolic blood pressure $<100 \mathrm{mmHg}$ or a decrease of $>20 \%$ from baseline), postpartum urinary retention, postdural puncture headache (PDPH), and transient neurological deficits. Complete loss of cold sensation to T8 on both sides was regarded as a dense block. Analgesia was maintained throughout the labor and delivery with an intermittent (hourly) bolus injection of $5 \mathrm{~mL} 0.125 \%$ bupivacaine.

The term "failed epidural" was used for situations in which either it was impossible to insert the catheter or there was no sensory block after injection of the local anesthetic. Unilateral block, unblocked sacral segments, low-level and unblocked segments or a patchy block were regarded as "incomplete block" before second stage of labor. If an "incomplete block" situation was observed, an additional $10 \mathrm{~mL}$ of $0.125 \%$ bupivacaine plain solution was administered in this group. If it persists despite the additional dose, it was accepted as persistent incomplete block before second stage, and intravenous analgesia was administered and such patient also was excluded from the study.

Blood pressure, heart rate and oxygen saturation were measured and recorded every 5 minutes for the duration of the labor. Hypotension (systolic blood pressure $<70 \%$ of baseline), bradycardia (heart rate $<50$ beats/min) and desaturation $\left(\mathrm{SpO}_{2}<90 \%\right)$ were recorded. Hypotension was treated with intravenous ephedrine $5 \mathrm{mg}$ and bradycardia with $0.5 \mathrm{mg}$ of intravenous atropine; desaturation was treated with oxygen via a facemask. The duration of labor, time taken to locate the epidural space, catheter-related complications encountered and amount of intravenous fluid given were documented.

For the non-epidural group, the women in labor received intravenous $30 \mathrm{mg}$ pentazocine $/ 25 \mathrm{mg}$ promethazine intravenously at cervical dilatation of $4 \mathrm{~cm}$. No additional analgesics were given until the end of second stage of labor. All the patients in this group were also closely monitored for oxygen saturation $\left(\mathrm{SPO}_{2}\right)$. Adverse reactions that occurred were recorded. Naloxone injection was drawn up and labeled in preparation to treat associated respiratory depression following the pentazocine administration.

The study ended at the time of vaginal delivery, spontaneous or with vacuum extraction; or when the decision was made to perform a cesarean delivery for any reason.

A 3-point satisfaction scale (adequate, inadequate and not sure) was used in both groups to assess the adequacy of pain relief with the chosen method. Immediate neonatal outcome was assessed using the Apgar scores.

\section{Statistical analysis}

Demographic variables were assessed using descriptive statistics. Other outcomes were evaluated using unpaired Student $t$ test and chisquare analysis. $P<0.05$ was considered significant. The primary outcome was to assess the acceptability of epidural pain relief in labor. According to a priori power analysis, 50 patients were sufficient to provide $90 \%$ power to detect the difference between the 
groups, accepting a two-tailed error of $5 \%$. However, the study patients in whom pain relief method was converted into another form were excluded. A post hoc power analysis was performed with respect to the observed difference of 72.9-89.6\%, with the sample size of 25 in each group. The power was calculated as $84 \%$ with a two-tailed error of $5 \%$.

\section{Results}

Fifty multiparous women in labor participated throughout the study. None of them requested to receive the other option of analgesia.

The socio-demographic data is shown in Table 1. The epidural group and the non-epidural group were comparable in terms of maternal age, level of parity and gestational age of pregnancy. The epidural labor analgesia and parenteral opioid/sedative were administered when the cervical dilatation attained $4 \mathrm{~cm}$. There was no statistical difference in the birth weights between the two groups $(P=0.33)$.

Table 2 shows the labor characteristics and outcome of the procedures. The mean duration of the first stage of labor was shorter in the epidural group; the difference was statistically significant $(P<0.01)$. The second stage of labor was also shorter in the epidural group than that in the non-epidural group; this difference was also statistically significant $(P<0.02)$. More women had oxytocin augmentation in the epidural group than in the non-epidural group. There were more spontaneous vaginal deliveries in the epidural group than in the non-epidural group. The total number of cesarean section deliveries did not differ significantly between patients receiving epidural analgesia (32\% [8/25]) and those receiving parenteral opioid/sedative (44\% [11/25]) for labor (OR, 0.60; 95\% CI, 0.19-1.90). The maternal blood loss following delivery was minimal in both groups; there was no statistically significant difference between the two groups $(P=0.27)$. The

\begin{tabular}{lccc}
\hline \multicolumn{4}{l}{ Table 1: Bio-demographic data } \\
& EG & NON-EG & $P$-value \\
\hline Maternal age in years & $28.6 \pm$ & $29.1 \pm$ & 0.80 \\
& 4.8 & 5.1 & \\
Parity & $2.9 \pm$ & $3.0 \pm$ & 0.90 \\
& 1.0 & 0.9 & \\
Gestational age & $39.0 \pm$ & $38.8 \pm$ & 0.60 \\
& 1.0 & 0.8 & \\
Cervical dilatation at & 4.0 & 4.0 & \\
request of analgesia & & & \\
Birth weight (grams) & $2955.7 \pm$ & $3089.3 \pm$ & 0.33 \\
& 417.5 & 304.5 & \\
\hline
\end{tabular}

Mean \pm standard deviation, EG: Epidural Group, NON-EG: Non-epidural Group neonatal outcome was the same in both groups, and there were no indications for admission to the special care baby unit (SCBU).

The experiences of the women are shown in Table 3. These questionnaires were administered 1 hour post-delivery. The overall experience of labor was much better in the epidural group when compared with that in the non-epidural group ( $80 \%$ versus $4 \%)$. Sixty-eight percent of the women in the nonepidural group could remember some of the pains of labor, while $65 \%$ of the women in the epidural group could not remember anything about labor pains. Sixty-four percent of the women in the epidural group felt completely in control, while $52 \%$ of the women in the non-epidural group felt they were not in control. More women felt sick during labor in the non-epidural group (64\%) than in the epidural group (24\%). Eighty-four percent of the women in the epidural group and $20 \%$ in the non-epidural group were not worried about the effects of the type of pain relief received during labor. Twenty-two $(88 \%)$ and $4(16 \%)$ women had adequate pain relief from epidural labor analgesia and parenteral opioid/ sedative, respectively. However, 18 (72\%) women claimed to have inadequate pain relief in the nonepidural group as compared to $2(8 \%)$ women in the epidural group.

Comments and views of the women are shown in Table 4. The women recruited to have epidural labor analgesia were more satisfied, as evidenced by the comments from them, than those women who had parenteral opioid/sedative.

\begin{tabular}{lccc}
\hline \multicolumn{4}{l}{ Table 2: Labor characteristics and outcome } \\
\hline Variable & EG & NON-EG & $P$-value \\
\hline Duration of & $173.9 \pm$ & $194.4 \pm$ & 0.01 \\
first stage & 11.2 & 25.1 & \\
Duration of & $23.5 \pm$ & $28.5 \pm$ & 0.02 \\
second stage & 4.8 & 3.3 & \\
Oxytocin & 7 & 3 & \\
augmentation & & & 0.60 \\
Mode of delivery & & & \\
$\quad$ Normal delivery & $17(68)$ & $14(56)$ & \\
Emergency & $8(32)$ & $11(44)$ & \\
$\quad$ cesarean section & & & \\
Post-delivery & & & \\
events & & & \\
$\quad$ Retained placenta & $2(8)$ & $3(12)$ & \\
Episiotomy & $12(48)$ & $15(60)$ & \\
Maternal & $149.7 \pm$ & $136.3 \pm$ & \\
blood loss & 37.2 & 27.1 & \\
Neonatal outcome & & \\
Apgar 1 minute & & \\
$>7$ & $23(92)$ & $21(84)$ & \\
$<7$ & $2(4)$ & $3(12)$ & \\
Apgar 5 minutes & & \\
$<7$ & 0 & $1(4)$ & \\
\hline Mean \pm standard deviation, number (percentage) & \\
& &
\end{tabular}




\begin{tabular}{|c|c|c|}
\hline & $\begin{array}{l}\text { Epidural } \\
\text { group }\end{array}$ & $\begin{array}{l}\text { Non-epidural } \\
\text { group }\end{array}$ \\
\hline \multicolumn{3}{|c|}{ Overall experience of labor } \\
\hline Worse than expected & 0 & $11(44)$ \\
\hline As expected & $5(20)$ & $13(52)$ \\
\hline Better than expected & $20(80)$ & $1(4)$ \\
\hline \multicolumn{3}{|l|}{$\begin{array}{l}\text { How much of the labor } \\
\text { pain do you remember? }\end{array}$} \\
\hline Nothing & $14(56)$ & $5(20)$ \\
\hline Some & $6(24)$ & $17(68)$ \\
\hline Everything & $4(16)$ & $3(12)$ \\
\hline \multicolumn{3}{|l|}{ Did you feel in control? } \\
\hline Not at all & $2(8)$ & $13(52)$ \\
\hline Some control & $7(28)$ & $9(36)$ \\
\hline Completely in control & $16(64)$ & $3(12)$ \\
\hline \multicolumn{3}{|l|}{$\begin{array}{l}\text { Were you actually } \\
\text { sick during labor? }\end{array}$} \\
\hline Yes & $6(24)$ & $16(64)$ \\
\hline No & $19(76)$ & $9(36)$ \\
\hline \multicolumn{3}{|l|}{$\begin{array}{l}\text { How sleepy were } \\
\text { you in labor? }\end{array}$} \\
\hline Not at all & $12(48)$ & $5(20)$ \\
\hline A little & $9(36)$ & $11(44)$ \\
\hline A lot & $3(12)$ & $9(36)$ \\
\hline \multicolumn{3}{|l|}{$\begin{array}{l}\text { Were you worried about } \\
\text { the effect of the pain } \\
\text { relief on your baby? }\end{array}$} \\
\hline Not worried & $21(84)$ & $5(20)$ \\
\hline Somewhat worried & $1(4)$ & $12(48)$ \\
\hline Extremely worried & $3(12)$ & $9(36)$ \\
\hline \multicolumn{3}{|l|}{$\begin{array}{l}\text { How would you grade } \\
\text { pain relief during labor? }\end{array}$} \\
\hline Adequate & $22(88)$ & $4(16)$ \\
\hline Inadequate & $2(8)$ & $18(72)$ \\
\hline Not sure & $1(4)$ & $3(12)$ \\
\hline
\end{tabular}

Number (percentage)

\section{Discussion}

Multiparous women without previous experience with labor analgesia were recruited for this study to ascertain their experiences. The overall experience of labor was better in the epidural group. The recruitment of patients to the non-epidural group was ethically based on patients' choice without unnecessarily denying them better pain relief.

Studies have found that epidural as compared with systemic opioid analgesia is associated with a prolonged first stage of labor. ${ }^{[12,13]}$ However, a surprising and clinically important finding of our study was that the durations of the first and second stages of labor were significantly shorter in the epidural group as compared to those in the non-epidural (systemic opioid/sedative) group. Factors that influence the progress of labor are not well understood. Autonomic imbalance has been proposed as an explanation for the association between epidural analgesia and prolonged labor. ${ }^{[13]}$ Tocodynamic studies have shown that

\begin{tabular}{ll}
\hline Table 4: Comments by patients \\
\hline Study group & Comments \\
\hline Epidural group & Have not had it this good \\
& You are godsend \\
& A must for every \\
& woman in labor \\
& This is a medical miracle \\
Non-epidural group & Pain was as expected \\
& The pain was more this time \\
& Pain was a little less this time \\
& Labor is scary \\
\hline
\end{tabular}

parasympathetic efferent nerves are blocked by neuraxial local anesthetics but presumably not by neuraxial opioids. ${ }^{[14,15]}$ The provision of effective analgesia decreases the inhibitory effect of endogenous maternal catecholamines on uterine contractility, attenuates maternal acidosis and permits maternal tolerance to oxytocin augmentation. ${ }^{[15]}$ This effect on the sympathetic system may explain why cervical dilatation was faster in women who received epidural labor analgesia in our study.

A positive association between epidural analgesia and the use of oxytocin to augment labor has been reported. ${ }^{[16]}$ In our study, more women received oxytocin augmentation in the epidural group than in the non-epidural group. Our study also shows that there was no statistically significant difference between the groups in the mode of delivery, although more cesarean sections were observed in the nonepidural group. Controversies have trailed the use of epidural labor analgesia with regard to the outcome of labor. ${ }^{[5,6]}$ Some studies advance that epidural labor analgesia prolongs labor and consequently increases cesarean section rates. ${ }^{[7,8]}$ Prolonged labor seems to occur more frequently when a higher dose of local anesthetic agent is used. ${ }^{[17]}$ However, this was not the case in our preliminary study, where a lower concentration $(0.125 \%$ bupivacaine $)$ was used.

The post-delivery events (incidence of retained placenta, rate of episiotomy and volume of maternal blood loss) were comparable in the two groups. Bodner-Alder et al., in their work, demonstrated the association between epidural labor analgesia and a higher rate of episiotomy. ${ }^{[18]}$ The fewer cases of episiotomy observed in our study might have been due to the parity of the women recruited. This confirms a report that lower rates of episiotomy during spontaneous vaginal births are associated with multiparity. ${ }^{[19]}$

A closed questionnaire was given to the women to express their views and also comment freely on the experiences with the forms of labor analgesia they received during childbirth. The overall experience of labor in the women who had epidural labor analgesia was much better (it was also better than 
expected) when compared with that in the women of the non-epidural group. This study confirms the findings of other investigators that epidural analgesia is a superior form of analgesia; ${ }^{[20,21]}$ consequently, more women are likely to ask for it. Most of the women in the non-epidural group did not feel they were in control of labor, unlike the $64 \%$ of the women in the epidural group. Not being in control during childbirth could probably be due to severe pain experienced by these women.

Maternal satisfaction during childbirth is an aspect of obstetric care that is gaining attention worldwide. Measuring satisfaction amongst obstetric patients is frequently associated with setbacks in terms of reliability and reproducibility. ${ }^{[22]}$ Being a clinical end point and an indicator of adequacy of care, satisfaction could provide a unique feedback on the quality of practice for medical specialties such as obstetric anesthesia. For parturient women, satisfaction with pain relief in labor can represent, at least in theory, an evaluation of obstetric care experience based on their values, perceptions and interactions with the health care environment. For labor analgesia care providers, maternal satisfaction can be used to assess the actual impact of such procedure on the patients. Regarding assessment with a three-point satisfaction scale in our study, $88 \%$ of the parturient women who had epidural labor analgesia claimed to have had adequate pain relief, while $72 \%$ of the women in the parenteral opioid/sedative group claimed to have had inadequate pain relief.

Satisfaction with childbirth is a multidimensional issue, of which analgesia is but one component. ${ }^{[23]}$ The importance of analgesia as a contributor to overall satisfaction has been recognized, but improvement in quality of available analgesia has not always resulted in commensurate improvement in satisfaction. Pain relief in childbirth is subject to many social and cultural modifiers, which continue to change. Control of pain rather than absolute amelioration is seen by many as providing greater satisfaction. ${ }^{[24]}$ Analgesia issues still do not Figure prominently in the overall satisfaction of the birthing process for the vast majority of women, despite the availability of, and demand for, improved methods of providing relief. The interpersonal relationships established between patients and health care providers may ultimately be of more importance in the determination of satisfaction with management. ${ }^{[25]}$ Satisfaction with the form of labor analgesia was further evidenced by the free comments made by these women.

Our study shows that epidural labor analgesia is acceptable to women in our setting, with no increase in adverse outcome. More women in the epidural analgesia group were satisfied with the experience of labor than those who had the pentazocine and phenergan combination for pain relief. With the concentration of local anesthetic used, there was no statistically significant difference in the cesarean section rates between the epidural labor analgesia group and the parenteral opioid/sedative group. There is an urgent need to establish a routine for epidural labor analgesia in our hospital as more women will be asking for this service.

Page | 255

\section{References}

1. Chamberlain G, Wraight A, Steer P. Pain and its relief in Childbirth. The results of a National Survey conducted by the National Birthday Trust, Churchill Livingstone, Edinburgh: 1993.

2. Akpan S, Eshiet A, Ilori I, Bassey E, Kalu Q, EdentekheT. Attitude of Nigerian mothers to labour pain and its relief. Mary Scelessor Journal of Medicine 2003;3:12-6.

3. Olayemi O, Aimakhu CO, Udoh ES. Attitudes of patients to obstetric analgesia at the University College Hospital, Ibadan, Nigeria. J Obstet Gynaecol 2003;23:38-40.

4. Imarengiaye CO. Trends in pain relief in labour: Implications for obstetric analgesia service in Nigeria. Niger Postgrad Med ] 2005;12:193-202.

5. Thorp JA, Parisi VM, Boylan PC, Johnston DA. The effect of continuous epidural analgesia on caesarean section for Dystocia in nulliparous women. Am ] Obstet Gynecol 1989;161:670-5.

6. Sharma SK, Sidawi JE, Ramin SM, Lucas M], Leveno K], Cunningham FG. Caesarean delivery: A randomized trial of epidural versus patient-controlled meperidine analgesia during labour. Anaesthesiology 1997;87:487-94.

7. Thorp JA, Eckert LO, Ang MS, Johnston DA, Peaceman AM, Parisi VM. Epidural analgesia and caesarean section for Dystocia: Risk factors in nulliparas. Am J Perinatol 1991;8:402-10.

8. Lieberman E, Lang JM, Cohen A, D’Agnostino R Jr, Datta S, Frigoletto FD Jr. Association of epidural analgesia with caesarean delivery in nulliparas. Obstet Gynecol 1996;88:993-1000.

9. Bofill JA, Vincent RD, Ross EL, Martin RW, Norman PF, Werhan CF, et al. Nulliparous active labour, epidural analgesia and caesarean delivery for Dystocia. Am J Obstet Gynecol 1997;177:1465-70.

10. Reynolds F, Crowhurst JA. Opioids in labour: No analgesic effect. Lancet 1997;349:4-5

11. Wijma K, Söderquist ], Wijma B. Post-traumatic stress disorder after childbirth: A cross sectional study. ] Anxiety Disord 1997;11:587-97.

12. Thorp JA, Hu DH, Albin RM, McNitt ], Meyer BA, Cohen GR, et al. The effect of intrapartum epidural analgesia on nulliparous labor: A randomized, controlled, prospective trial. Am J Obstet Gynecol 1993;169:851-8.

13. Halpern SH, Leighton BL, Ohlsson A, Barret JF, Rice A. Effect of epidural vs parenteral opioids analgesia on the progress of labor: A meta-analysis. JAMA 1998;280:2105-10.

14. Neumark ], Hammerle AF, Biegelmayer C. Effects of epidural analgesia on plasma catecholamines and cortisol in parturition. Acta Anaesthesiol Scand 1985;29:555-9.

15. Schnider SM, AbboudTK, Artal R, Henriksen EH. Maternal catecholamine decreases during labour after lumbar epidural anaesthesia. Am J Obstet Gynecol 1999;147:13-5.

16. Zhang J, Klebanoff MA, DerSimonian R. Epidural analgesia in association with duration of labor and mode 
of delivery: A quantitative review. Am ] Obstet Gynecol 1999;180:970-7.

17. Olofsson C, Ekblom A, Ekman-Ordeberg G, Irestedt L. Obstetric outcome following epidural analgesia with bupivacaine-adrenaline $0.25 \%$ or bupivacaine $0,125 \%$ with sufentanil: A prospective randomized controlled study in 1000 parturients. Acta Anaesthesiol Scand 1998;42:284-92.

18. Bodner-Adler B, Bodner K, Kimberger O, Wagenbichler P, Kaider A, Husslein P, et al. The effect of epidural analgesia on the occurrence of obstetric lacerations and on the neonatal outcome during spontaneous vaginal delivery. Arch Gynecol Obstet 2002;267:81-4.

19. Otoide VO, Ogbonmwan SM, Okonfua FE. Episiotomy in Nigeria. Int ] Gynaecol Obstet 2000;68:13-7.

20. Robinson JO, Rosen M, Evans JM, Revill SI, David $H$, Rees GA. Maternal opinion about analgesia in labour: A controlled trial between epidural block and intramuscular pethidine combined with inhalational. Anaesthesia 1980;35:1173-81.
21. Phillipsen T, Jensen NH. Maternal opinion about analgesia in labour: A comparison of epidural blockade and intramuscular pethidine. Eur ] Obstet Gynecol Reprod Biol 1990;34:205-10

22. Fung $D$, Cohen MM. Measuring patient satisfaction with anaesthesia care: A review of current methodology. Anesth Analg 1998;87:1089-98.

23. Hodnett ED. Pain and women's satisfaction with the experience of childbirth: A systematic review. Am J Obstet Gynecol 2002;186: S160-72.

24. Lebovits AH, Zenetos P, O'Neil DK, Cox D, Dubois MY, Jansen LA, et al. Satisfaction with epidural and intravenous patient controlled analgesia. Pain Med 2001;2:280-6.

25. Ross A. Maternal satisfaction with labour analgesia. Baillieres Clin Obstet Gynaecol 1998;12:499-512.

Source of Support: Nil, Conflict of Interest: None declared. 